Der Hanns-Lilje-Preis 2010 wurde Herrn Gregor Emmenegger, Freiburg/ Schweiz, für seine Arbeit „Der Text des koptischen Psalters aus al-Mudil“ verliehen.

\title{
Der Text des koptischen Psalters aus al-Mudil
}

\section{Gregor EMMENEGger}

Der Codex aus al-Mudil gehört zu den Prunkstücken des Koptischen Museums in Kairo. Der in ihm erhaltene Text ermöglicht vielfältige Einsichten in die Textgeschichte der Bibel.

Al-Mudil befindet sich in Mittelägypten, in der Nähe des antiken Oxyrhynchos. 1984 wird dort ein Gräberfeld ausgegraben, das im vierten Jahrhundert nach Christus angelegt worden ist. Die Gräber sind ärmlich, man entdeckt neben den mumifizierten sterblichen Überresten etwas Holzschmuck und Amulette. Mit einer Ausnahme: In einem Grab findet man die Mumie eines jungen Mädchens. Unter ihrem Kopf liegt eine Pergamenthandschrift der biblischen

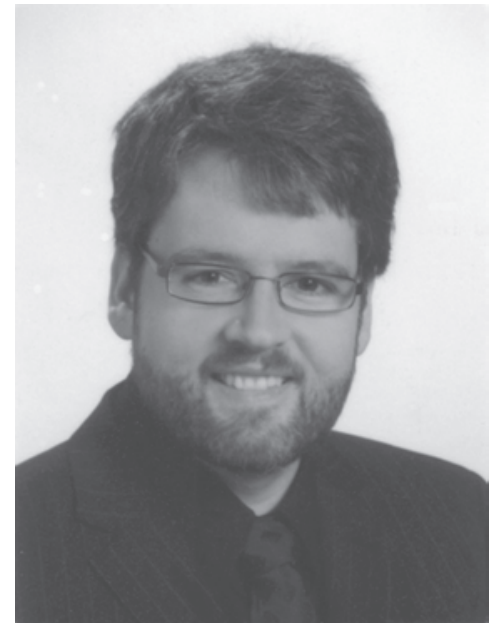

Gregor Emmenegger, Lehr-und Forschungsrat an der Universität Freiburg/Schweiz, Träger des HannsLilje-Preises 2010 Psalmen. Der Codex ist in Mesokemisch abgefasst, einem koptischen Dialekt - der Alltagssprache der Bauern in der Region um Oxyrhynchos im vierten Jahrhundert. Aufgrund seines hohen Alters und seiner selten überlieferten Sprache war der Fund eine Sensation. ${ }^{1}$ Doch noch interessanter ist der in ihm enthaltene Text. Warum?

Die Antwort auf diese Frage hängt mit dem Göttinger Professor Alfred Rahlfs zusammen. Diesem gelang es vor etwa hundert Jahren, eine Geschichte des Textes des griechischen Psalters, des sogenannten SeptuagintaPsalters, zu rekonstruieren. ${ }^{2}$

\footnotetext{
$1 \quad$ Die Ausgrabung ist nicht dokumentiert worden, und auch die übrigen Fundgegenstände sind nicht auffindbar, so dass genauere Angaben nicht möglich sind. Vgl. Gawdat Gabra, Der Psalter im oxyrhynchitischen (mesokemischen / mittelägyptischen) Dialekt, Heidelberg 1995.

2 Alfred Rahlfs, Der Text des Septuagintapsalters (Septuagintastudien 2), Göttingen 1907.
} 


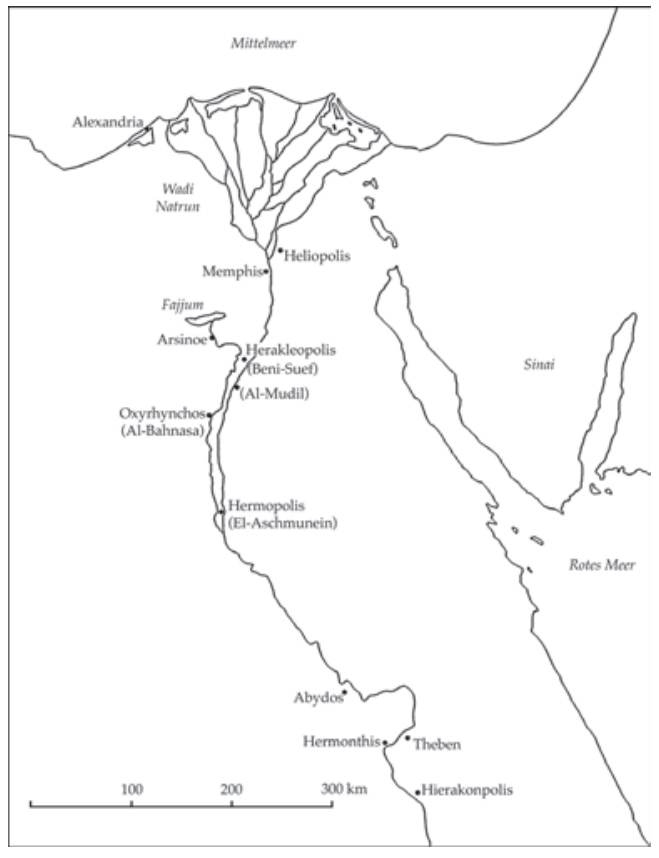

Abbildung 1: Karte Ägyptens in der Spätantike. Moderne Namen sind in Klammern gesetzt.

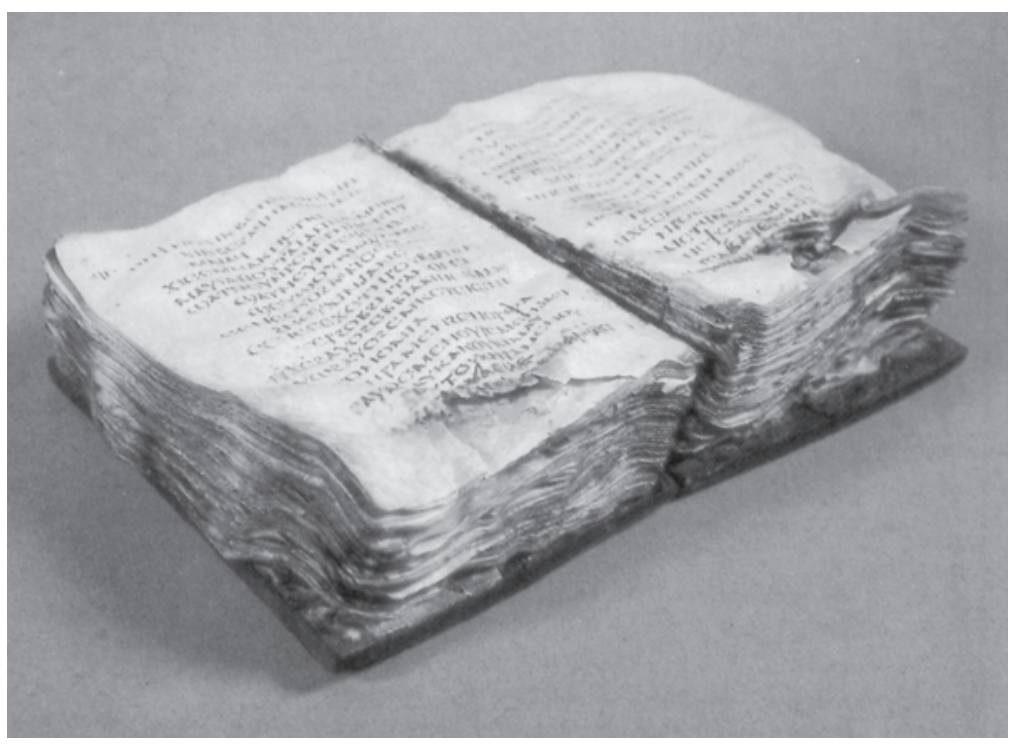

Abbildung 2: Der Mudil-Codex (C Koptisches Museum Kairo) 
Die Psalmen sind ursprünglich auf Hebräisch verfasst. Im zweiten Jahrhundert vor Christus wurden sie in die damalige Verkehrssprache Griechisch übersetzt - zu einer Zeit also, als der hebräische Text selbst noch nicht festgelegt war. Es gab mehrere verschiedene Versionen der Psalmen. Auch die neu entstandene griechische Übersetzung befand sich im Fluss. Weil die Übersetzer manchmal sklavisch wörtlich und manchmal sehr frei gearbeitet haben, wurde sie in den folgenden Jahrhunderten immer wieder korrigiert und ausgebessert. Diese griechische Übersetzung fand weite Verbreitung in der jüdischen Diaspora und wurde zum Standard bei den frühen Christen.

Wir wissen nicht genau, welchen Psalmentext etwa Paulus auf seinen Reisen verwendet hat. Obwohl viele Handschriften der Psalmen überliefert sind, sind vom vor- und vom frühchristlichen Psaltertext nur noch Spuren erhalten geblieben. Der Grund hierfür ist folgender: Wie bei dem bekannten Flüsterspiel haben sich mit den Jahrhunderten von Kopist zu Kopist Fehler in den Text eingeschlichen. Es wurde geschickt und weniger geschickt korrigiert, ausgebessert und angepasst. Und auch der hebräische Text hat sich gewandelt und ist standardisiert worden. In den grossen Zentren begann man, den griechischen Text der Psalmen konsequent zu überarbeiten. Diese Rezensionen verdrängten den alten Text. Nur an abgelegenen Orten ist die alte Version erhalten geblieben und hat dort ein lokales Gepräge angenommen - zum Beispiel in Oberägypten.

Mit der Christianisierung Ägyptens im dritten Jahrhundert wurde es notwendig, der nicht griechisch sprechenden Bevölkerung die Bibel zugänglich zu machen - sie musste in die Volkssprache Koptisch übersetzt werden. Die in der Folge entstandenen Übertragungen des Alten Testaments sind durchwegs Übersetzungen aus dem Griechischen und nicht aus dem Hebräischen. Und tatsächlich wurde als Vorlage für die oberägyptischen Übersetzungen dieser alte, unrezensierte griechische Psalmentext verwendet. So ist ein allerdings schon recht verderbter Text konserviert worden. Rahlfs spricht anschaulich von einem archaischen, verwilderten Text.

Anders verhält es sich bei dem Mudil-Kodex. Der in ihm enthaltene Text ist frei von vielen dieser sogenannten Verwilderungen. Dennoch zeigt er etliche Merkmale des unrezensierten Textes. Darum war die Hoffnung gross, dass im Mudil-Kodex endlich dieser frühe griechische Text in einer reinen Form greifbar sei. Man hätte so einen Anhaltspunkt, wie die Psalmen zur Zeit der Abfassung des Neuen Testaments ausgesehen hätten, und könnte auf die verwendete hebräische Vorlage rückschliessen. Das ist die Ausgangslage für meine Dissertation. 
Um die Frage zu beantworten, ob der Mudil-Kodex diesen unrezensierten Psalmentext wiedergibt, habe ich den Text mit den wichtigsten Textzeugen verglichen: mit den hebräischen und den griechischen Ausgaben aus späterer Zeit, mit der Version aus Qumran sowie mit den verschiedenen griechischen und koptischen Versionen, die meist fragmentarisch auf Papyrus, Pergament oder Holz aus jener Zeit erhalten sind.

An einem Beispiel möchte ich illustrieren, was das bedeutet und von welcher Art die Varianten sind, von denen ich hier spreche:

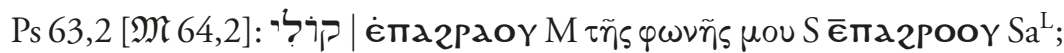

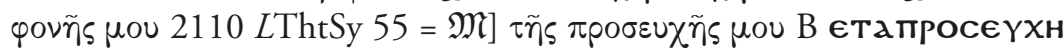
Bo $\mathrm{R}$ orationem meam $\mathrm{LaGaHe}$

Dies bedeutet: In Psalm 63,2 steht „Höre, Gott, auf“ - und der masoretische Text fährt fort: קרל?: „meine Stimme“. Der Mudil-Codex (M) liest

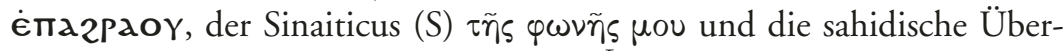
setzung nach dem Papyrus von London $\left(\mathrm{Sa}^{\mathrm{L}}\right) €$ €ra2pooY, das bedeutet „die meine Stimme“. Auch der Papyrus Bodmer (2110) und die Mehrheitstexte (L Tht Sy 55) lesen $\varphi \omega \nu \tilde{\eta} \varsigma \mu$ ou „meine Stimme“, lassen aber den Artikel $\tau \tilde{\eta} \varsigma$ aus. Diese Zeugen stimmen alle mit dem masoretischen Text $(\mathfrak{M})$ überein. Anders jedoch die unterägyptischen und die abendländischen Zeugen: Sie

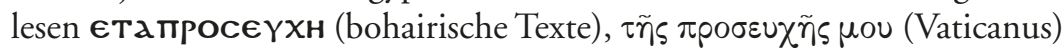
und orationem meam (Altlateinische Versionen) - „mein Gebet“.

Von solchen Varianten habe ich einige Tausend zusammengetragen. Anschließend habe ich diese Abweichungen gruppiert: Abschreibfehler, Übersetzungsfehler, Korrekturen, Anpassungen und natürlich all jene Differenzen, an denen mein Text mit einem oder mit mehreren der anderen Textzeugen übereinstimmt.

Das Ergebnis erstaunt: Der Mudil-Kodex kann nicht den alten, unrezensierten Text enthalten. Er zeigt Berührungen mit verschiedenen Textzeugen - oft zu sehr alten Versionen, aber an einigen Stellen auch zu den Rezensionen des dritten oder des vierten Jahrhunderts. Mit anderen Worten: Der Text des Mudil-Codex insgesamt kann nicht bedeutend älter sein als der Codex selbst. Die Handschrift ist ein Beispiel dafür, dass man sich in jener Zeit nicht nur in den grossen Zentren der Christenheit um einen guten Text bemüht hat, sondern auch an abgelegenen Orten wie in Mittelägypten. Und dies ist so gut ausgeführt worden, dass der Text auch heute auf den ersten Blick deutlich älter erscheint, als er tatsächlich ist.

Der Grund dafür liegt in der Arbeitsweise: Zwar lassen sich Anzeichen dafür erkennen, dass der Redaktor des al-Mudil-Codex über eine exegetische Bildung verfügte. Doch er verfolgte andere Motive und wendete 
andere Methoden an als die hochgelehrten Exegeten Origenes, Lukian oder Hieronymus, die in jener Zeit am Bibeltext arbeiteten. Es ging ihm nicht darum, seinen Text an der, wie Hieronymus es nennt, „hebraica veritas“, der hebräischen Wahrheit zu messen.

Oxyrhynchos entwickelt sich in jener Zeit zu einem monastischen Zentrum. Aus dem ganzen Reich kommen Leute, um bei den berühmten Wüstenvätern in Askese und Mystik unterwiesen zu werden. Der Psalter spielt im religiösen Leben der Mönche eine zentrale Rolle - viele können ihn auswendig. Doch nicht zuletzt beim gemeinsamen Psalmenbeten müssen Differenzen verschiedener Textversionen aufgefallen sein. Diesen Mangel will der Redaktor beheben. Er erstellt einen Kompromisstext zum alltäglichen Gebrauch in der Sprache seines Wohnortes. Zu diesem Zweck vergleicht er griechische und koptische Psalter, die schon im Umlauf sind und denen eine gewisse Autorität zugeschrieben wird. Er erarbeitet daraus einen Mischtext, eine Art „Einheitsübersetzung“. Er versucht, bei differierenden Varianten allen Vorlagen möglichst gerecht zu werden. Manchmal passt er den Text sogar seinen eigenen theologischen Vorstellungen an. Nur so lassen sich die zahlreichen Sonderlesarten und Harmonisierungen wie auch die unterschiedlichen Abhängigkeiten und Berührungen erklären.

Weitere Untersuchungen zeigen, dass in Oxyrhynchos einige andere Texte zur selben Zeit in vergleichbarer Weise überarbeitet worden sind. Der Übersetzer kann folglich als Exponent einer lokalen Schule gelten. Die Arbeitsmethode, die sich an den Psalmen des Mudil-Kodex gut dokumentieren lässt, ist zudem bei Zeugen des griechischen Neuen Testaments nachweisbar.

Der Text des Psalters aus al-Mudil verdient in der Textgeschichte der Bibel einen Ehrenplatz. Er ist ein wichtiger Zeuge für zum Teil sehr alte Textvarianten. Vor allem aber ist er ein faszinierendes Beispiel dafür, wie im Ägypten des vierten Jahrhunderts mit Bibeltexten umgegangen wurde. Der Codex bezeugt die auch heute noch nicht selbstverständliche Einsicht, dass Heilige Schrift nur in verschiedenen Versionen zugänglich ist. Heilige Texte haben ihre Geschichte, sie verändern sich mit den Jahrhunderten und müssen deshalb studiert und gepflegt werden, sei es hier am SeptuagintaUnternehmen oder in einem spätantiken ägyptischen Kloster. 